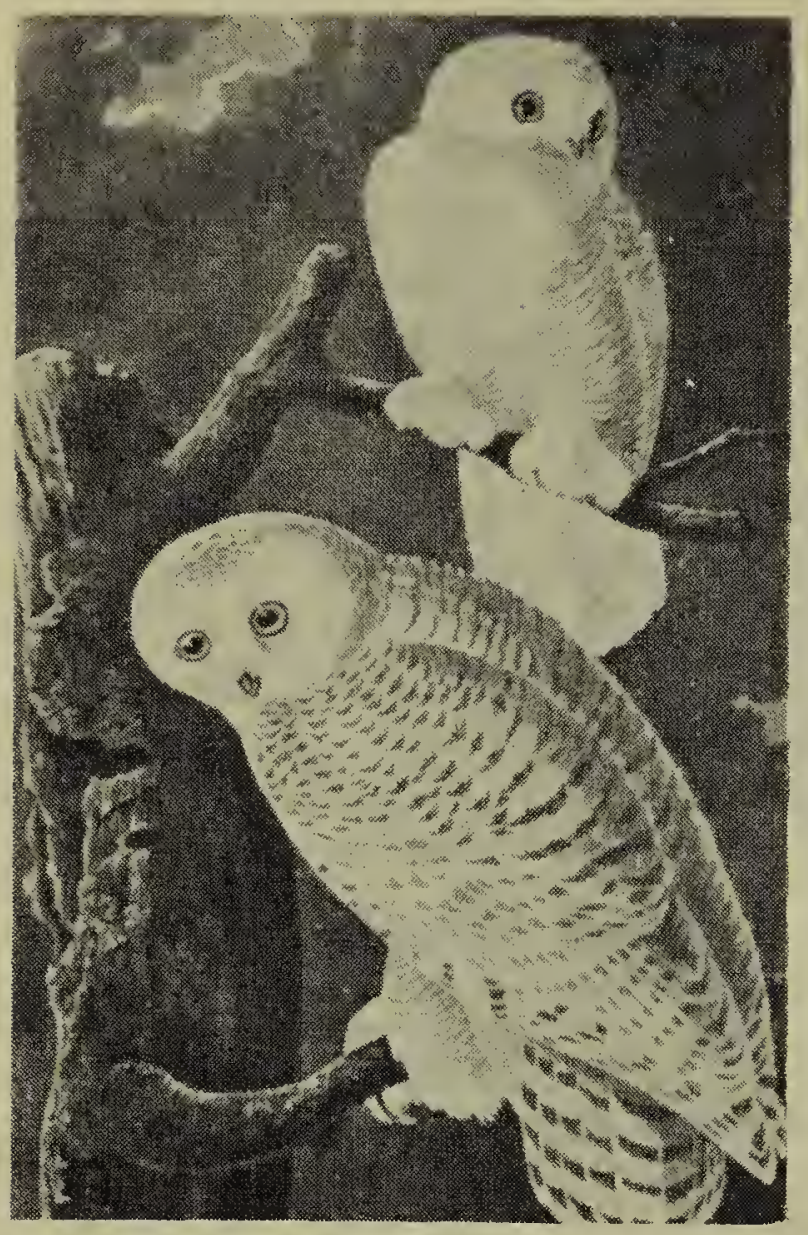

\section{Snowy Owls Plentiful}

T. M. Beveridge, Pathlow

D URING my frequent drives through the country I find that, apart from English Sparrows and Magpies, Snowy Owls are the species most regularly observed. Few drives were taken during the daylight without seeing one or more; frequently three or four; once, December 9, at least seven. Snow Buntings appear in considerable numbers at times. Other winter birds are not numerous. Three Redpoles were observed November 10, two Pine Grosbeaks November 8 and 10, one Blue Jay November 30, Northern Shrikes on October 30, November 7 and December 5. I have not noticed Hairy Woodpeckers more than half a dozen times and have seen no Downies since winter set in.

\section{A BLUE JAY AT GRENFELL}

Mrs. Bilsbury reports that on October 7 last she saw the first Blue Jay that had come into the locality for many years. The last one seen was about eight years ago on a farm about a mile distant.

\section{Birds Banded at Nipawin}

January 1, 1951, to January 1, 1952 Maurice Street

Species , Matthews Street

Redtailed Hawk ..........................

Marsh Hawk

Long-eared Owl ..........................

Hairy Woodpecker ............. ... 3

Eastern Kingbird ............... 5 ...

Eastern Phoebe ...................... 11

Least Flycatcher ................... 112

Horned Lark ................................ 1 (...

Barn Swallow ............................ 7 ...

Canada Jay ................................. $4 \quad \ldots$

Blue Jay ..................................... ... 4

$\begin{array}{lll}\text { Black-capped Chickadee } & 1 & 7 \\ \text { Red-breasted Nuthatch... } & \ldots & 1\end{array}$

House Wren .................................. 1

Eastern Robin ........................ $30 \quad 30$

Hermit Thrush .............................

Olive-backed Thrush ......

Gray-cheeked Thrush ...........

American Pipit ......................... 11 ...

Bohemian Waxwing .........

Northern Shrike ...................... ... $\quad 2$

White-rumped ......................... 7 ...

Tennessee Warbler ............. 1

Magnolia Warbler ....................

Myrtle Warbler ..................... 2

Bay-breasted ...................................

Black-poll Warbler .............. 1

Palm Warbler ............................ 5

Oven-bird ...........................................

Waterthrush ...................................

Mourning Warbler ............. 1

Yellow-throat ………......................

Wilson's Warbler ....................... ... 1

Am. Redstart ..................................

Western Meadowlark ...... 1

Cowbird ......................................... ... 1

Evening Grosbeak ................ ... $\quad \begin{array}{r}8 \\ \text { Pine Grosbeak }\end{array}$

$\begin{array}{lr}\text { Pine Grosbeak ........................... } \quad \ldots . . & 10 \\ \text { Purple Finch ............................ } & 37\end{array}$

Hoary Redpoll ......................... 17

Common Redpoll ....................396 511

Pine Siskin ..................................... 7

Am. Goldfinch ........................ 1

Savannah Sparrow ............ 22

Vesper Sparrow ....................... 41

Slate-col. Junco ........................155

Tree Sparrow ............................. 1

Chipping Sparrow ............... 2

Clay-col. Sparrow ............... 21

Harris's Sparrow ................... 12

Gambel's Sparrow ............ 2

White-thro. Sparrow ...... 93

Fox Sparrow ............................... 4

Lincoln's Sparrow ................ 18

Song Sparrow ............................. 46

Species ................................................ 34

Totals ……………………………....949 